Liebl, Maik; Steinhoff, Uwe; Wiekhorst, Frank; Schwarz, Kai; Zirpel, Peter; Gutkelch, Dirk; Trahms, Lutz; Haueisen, Jens:

\title{
Spatial reconstruction of a magnetic nanoparticle distribution using a single sensor and multiple magnetizing coils
}

Zuerst erschienen in: Biomedical Engineering = Biomedizinische Technik. - Berlin [u.a.] : de Gruyter. - 57 (2012), Suppl. 1, Track-M, p. 747.

Erstveröffentlichung: $\quad$ 2012-09-04

ISSN (online): $\quad$ 1862-278X

ISSN (print): $\quad$ 0013-5585

DOI: $\quad 10.1515 / \mathrm{bmt}-2012-4021$

[Zuletzt gesehen: 2019-08-15]

„Im Rahmen der hochschulweiten Open-Access-Strategie für die Zweitveröffentlichung identifiziert durch die Universitätsbibliothek IImenau."

"Within the academic Open Access Strategy identified for deposition by Ilmenau University Library."

„Dieser Beitrag ist mit Zustimmung des Rechteinhabers aufgrund einer (DFGgeförderten) Allianz- bzw. Nationallizenz frei zugänglich."

"This publication is with permission of the rights owner freely accessible due to an Alliance licence and a national licence (funded by the DFG, German

Research Foundation) respectively." 


\title{
Spatial reconstruction of a magnetic nanoparticle distribution using a single sensor and multiple magnetizing coils
}

\author{
M. Liebl ${ }^{1,2}$, U. Steinhoff ${ }^{1}$, F. Wiekhorst ${ }^{1}$, K. Schwarz ${ }^{1}$, P. Zirpel ${ }^{1}$, D. Gutkelch ${ }^{1}$, L. Trahms ${ }^{1}$, J. Haueisen ${ }^{2}$ \\ ${ }^{1}$ Physikalisch-Technische Bundesanstalt, Berlin, Germany \\ ${ }^{2}$ Ilmenau University of Technology, Institute of Biomedical Engineering and Informatics, Ilmenau, Germany
}

\section{Introduction}

Quantitative spatially resolved imaging of magnetic nanoparticles (MNP) is essential for the control of new MNP-based therapies against cancer. In magnetorelaxometry (MRX) a distribution of nanoparticles is quantified by measuring its relaxation after changing an external magnetic field. Previous theoretical work suggests an improvement of the spatial resolution by sequential application of inhomogeneous excitation fields. Here we experimentally tested this hypothesis using a single-sensor setup.

\section{Methods}

The MRX setup consisted of 30 magnetizing coils $(\mathrm{d}=6 \mathrm{~mm})$ radially placed on the surface of a cylinder $(5$ rings with $\mathrm{h}=7.5 \mathrm{~mm}, 6$ coils with phi $=60^{\circ}$ per ring). The volume directly outside the cylinder surface was divided into 9 subvolumes (voxels). In each of the 9 voxels an MNP-sample (300 mg iron oxide powder) was sequentially magnetized by the 30 magnetization coils and the relaxation response was measured by a single SQUID system. The voxel magnetization was reconstructed by inverting the forward problem of 30 equations relating magnetizing field and relaxation amplitude using a Truncated Singular Value Decomposition. The reconstruction of more complex source distributions was evaluated on superpositions of the results of the single voxel measurements.

\section{Results}

The measurement of MRX signals using 30 excitation coils was feasible. A quantitatively accurate reconstruction of the amount of nanoparticles was achieved for all single voxels and also for complex distributions. The mean difference between the reconstructed MNP amount and the actual value was about 10 percent. Meaningful reconstructions were also obtained after virtual enlarging the spatial resolution up to 9 by 9 voxels.

\section{Conclusion}

We demonstrated the possibility of MNP imaging with MRX using inhomogeneous magnetizing fields and only one sensor. Further works will focus on larger source volumes and multi-sensor systems. 